\title{
Analisis Faktor yang Berhubungan dengan Budaya Keselamatan Pasien pada Perawat di Ruang Rawat Inap RSUD Arifin Achmad Provinsi Riau
}

\author{
Yeni Yarnita ${ }^{1 *}$, Efitra $^{2}$ \\ ${ }^{1}$ Dosen Keperawatan Universitas Muhammadiyah Riau \\ ${ }^{2}$ Dosen Poltekes Kemenkes Padang \\ ${ }^{*}$ Correspondence email: yeniyarnita@umri.ac.id
}

\begin{abstract}
Abstrak. Budaya keselamatan pasien merupakan salah satu unsur penting dalam pelaksanaan keselamatan pasien di rumah sakit. Sehingga dapat dieliminisir kejadian yang tidak diharapkan (KTD). Data rumah sakit menunjukkan masih terdapat KTD pada tiap tahunnya. Penelitian bertujuan untuk mengetahui faktor-faktor yang berhubungan dengan budaya keselamatan pasien pada perawat diruang Rawat Inap RSUD Arifin Achmad Provinsi Riau. Populasi adalah seluruh perawat pelaksana di RSUD Arifin Achmad Provinsi Riau dengan besar sample 131 perawat dengan teknik cross sectional probability sampling. Pengumpulan data dengan cara angket analisis data dengan distribusi frekuensi, chi square dan uji regresi logistik. Hasil penelitian didapat ada hubungan sikap $(v$ palue 0.001$)$, tim kerja $(v$ palue 0,017$)$, kelelahan $(0,013)$ dengan budaya keselamatan. Namun stres kerja tidak berhubungan dengan budaya keselamatan pasien $v$ palue 0,139 . Hasil penelitian didapatkan sikap merupakan faktor yang paling berhubungan dengan budaya keselamatan pasien. Disarankan kepada pihak manajemen rumah sakit untuk dapat melakukan pelatihan keselamatan pasien, menjadikan kepala ruangan sebagai role model dalam budaya keselamatan pasien
\end{abstract}

Kata kunci: budaya keselamatan; kerja tim; kelelahan; stres

\begin{abstract}
Safety patient culture was one of the important things in operating the safety patient in hospital, so that the unexpected incident can be minimized. the data Arifin Achmad Riau Province showed that the number exceeds the limit figure KTD specified tolerance ie $\geq 1.5 \%$ like numbers plebitif $5.81 \%$, and the incidence of patient falls are as much as five events in 2015. This research is aimed to know the factors which are related to the safety patient culture on nursing staff in hospitalization service room of Arifin Achmad Hospital, Riau Province. The population is all of the nursing staffs in Arifin Achmad Hospital, Riau Province with the sample is 131 nurses. This research uses cross sectional non probability sampling technique. The method in collecting the data is questionnaire and the method in analyzing the data are frequency distribution, chi square distribution and logistic regression test. The result of the research is obtained there is a relation between attitude ( $p$ value 0.001), team work ( $p$ value 0,017), fatigue $(0,013)$ with the safety culture, while the stress work does not related to the safety patient culture ( $p$ value 0,139 ). The result obtained that attitude is the most related factor with the safety patient culture. The writer suggests to the management of the hospital to be able to enhance the safety culture management support, improve peedback safety culture and communication between leaders and nurses, workforce analysis, structuring nurse station
\end{abstract}

Keywords: Safety culture; atittude; team work; fatigue; stress

\section{PENDAHULUAN}

Rumah sakit merupakan suatu wadah pelayanan kesehatan yang utama. Dengan demikian rumah sakit harus mampu memberikan pelayanan kesehatan yang terintegrasi pada pasien sebagai penguna layanan. Data tentang keselamatan pasien di dunia masih menunjukkan masalah yang signifikan. Institute of Medicine (IOM) pada tahun 2008 melaporkan angka KTD pada rumah sakit di Amerika Serikat yaitu 1.5 juta pasien terluka pertahun dari kesalahan pengobatan, data 7000 diantaranya dilaporkan meninggal (Webair, $\mathrm{H}$, et al,. 2015). Temuan hasil penelitian di negara Arab 2,5\% juta sampai $18 \%$ Kejadian Tidak Diharapkan terjadi pada pasien, dari data tersebut $83 \%$ kejadian dapat dicegah dari kejadian tersebut memiliki efek samping resiko terhadap kematian pasien (Najjar, et al,. 2013). Data yang cukup besar juga ditunjukkan oleh lembagalembaga kesehatan dunia dimana terdapat sebagian besar kejadian kesalahan medis dan adanya masalah dalam perawatan pasien (Aspden, et al,. 2007).
Secara garis besar yang dikatakan dengan budaya keselamatan pasien adalah keyakinan, persepsi, perilaku dan kompetensi individu atau kelompok dalam suatu organisasi yang mempunyai komitmen untuk bersamasama menciptakan lingkungan yang aman (Brady, et al,. 2012). Menciptakan budaya pelayanan kesehatan yang aman maka adanya tanggung jawab dari setiap petugas kesehatan untuk menanamkan nilai-nilai budaya keselamatan pasien disebuah rumah sakit. Nilai tersebut dapat berupa kedisiplinan, kepatuhan terhadap standar prosedur, dan protokol yang ada, teamwork, adanya nilai kejujuran dan keterbukaan serta rasa saling menghormati dan menghargai satu sama lain yang dijunjung tinggi oleh petugas, dikomunikasikan dan diajarkan dari dan ke setiap petugas, menjadi aturan yang ditaati sehingga membentuk kebiasaan dan perilaku setiap petugas dalam rumah sakit (Cahyono, 2008).

Sistem budaya keselamatan yang terdapat dalam organisasi dapat bersifat positif dengan adanya komunikasi terbuka yang berdasarkan nilai-nilai 
organisasi dan kepercayaan serta adanya persepsi yang didukung oleh anggota organisasi atau individu dalam suatu organisasi (Hammer, et al,. 2011). Menurut Raftopoulos (2013) diantara banyak faktor individu adanya sikap keselamatan merupakan hal yang berkaitan dengan budaya keselamatan pasien. Faktor lain yang berkaitan dengan budaya keselamatan adalah adanya komitmen dan gaya yang dianut dalam sebuah organisasi (Fujita, et al,. 2013). Adanya kerja sama tim merupakan bagian dari sebuah organisasi yang akan mempengaruhi budaya keselamatan pasien (Sammer \& James, 2011). Buerhaus, et al,. (2011) adanya faktor individu atau petugas sangat berpengaruh terhadap budaya keselamatan pasien, diantara faktor tersebut menunjukkan bahwa adanya keterlibatan tingkat stress dan tingkat kelelahan.

Rumah Sakit Umum Daerah Provinsi Riau adalah rumah sakit pemerintah tipe $B$ pendidikan dan merupakan rumah sakit rujukan utama di Provinsi Riau. Kinerja pelayanan RSUD Arifin Achmad Provinsi Riau dimana BOR pada tahun 2013 mencapai $72.58 \%$. Permenkes No 129/ Th. 2008 tentang Standar Pelayanan Minimal (SPM) Rumah Sakit menujukkan bahwa SPM ruang rawat inap yang berkaitan dengan pasien jatuh harus menunjukkan angka nol atau pada nilai "zerro defect" (tingkat insidensi $0 \%$ ) dalam tiap tahunnya

RSUD Arifin Achmad Provinsi Riau telah melaksanakan program keselamatan pasien sejak tahun 2012, dalam pelaksanaannya RSUD Arifin achmad telah memiliki KKP-RS, champions keselamatan pasien, sudah terdapat SPO tentang pelaksanaan keselamatan pasien, dan telah berjalannya sosialisasi tentang pelaksanaan keselamatan pasien serta telah diikut sertakannya pegawai rumah sakit khususnya perawat dalam berbagai pelatihan dan seminar yang berkaitan dengan keselamatan pasien di rumah sakit. Adanya sosialisasi tentang keselamatan pasien di ruangan seperti, adanya petunjuk serta manfaat keselamatan pasien yang ditempel pada papan pengumunan maupun pada dinding ruangan, telah terdapat SPO keselamatan pasien, namun dalam pelaksanaannya masih terdapat perawat yang belum memahami secara utuh tentang keselamatan pasien yang akan mempengaruhi persepsi dan sikap khususnya perawat sebagai lini terdepan dalam memberikan pelayanan asuhan keperawatn selama 24 jam terhadap pasien terhadap di ruang rawat inap. Berdasarkan hasil observasi dan wawancara yang dilakukan pada ruang rawat Inap RSUD Arifin Achmad Provinsi Riau yang dilakukan pada tanggal 19, 21 dan 26 Mei 2016 bahwa pelaksanaan keselamatan pasien masih menunjukkan adanya budaya keselamatan pasien yang lemah atau dengan kata lain masih terdapat budaya keselamatan pasien yang negatif. Hal ini dibuktikan dengan dari 12 dimensi keselamatan pasien masih terdapat beberapa dimensi keselamatan pasien yang belum terbentuk secara maksimal.
Hasil observasi ini terlihat pada dimensi staffing atau ketenagaan. Berdasarkan hasil observasi bahwa masih terdapat perawat yang melakukan pekerjaannya melebihi jam kerja yang ditetapkan. Hal ini terjadi baik pada shif pagi maupun siang. Bahwa adanya pekerjaan yang belum dapat diselesaikan pada saat waktu jam kerja berakhir menunjukkan bahwa masih tingginya beban kerja yang dirasakan oleh perawat pelaksana pada ruang rawat inap RSUD Arifin Achmad Provinsi Riau

\section{METODE}

Jenis penelitian ini adalah penelitian dengan pendekatan kuantitatif dengan analitik corelasi dan desain cross sectional. Dalam penelitian ini peneliti ingin mendapatkan gambaran masing-masing variabel penelitian serta menghubungkan dua variabel dan sub variabel masing-masing variabel dengan analisis kolerasi serta dengan melakukan penelitian sesaat pada waktu tertentu saja (Sastroasmoro, 2011)

Populasi merupakan keseluruhan jumlah objek atau subjek yang akan diteliti yang memiliki karakteristik dan kualitas tertentu yang ditetapkan oleh peneliti guna memperoleh kesimpulan dari hasil penelitian (Sugiyono, 2011). Populasi dalam penelitian ini adalah seluruh perawat pelaksana di Ruang Rawat Inap RSUD Arifin Achmad Provinsi Riau yang berjumlah 170 perawat. Sampel adalah objek yang diteliti yang merupakan sebagian dari jumlah dari populasi (Notoatdmojo, 2010; Sugiyono, 2011). Sampel dari penelitian ini adalah sebagian perawat pelaksana di ruang Rawat Inap RSUD Arifin Achmad Provinsi Riau dengan teknik pengambilan sampel yaitu menggunakan non probability sampling yaitu purposive sampling. Sampel dipilih dari populasi yang memenuhi kriteria inklusi dan eksklusi. Kriteria inklusi pada penelitian ini adalah:

1. Semua perawat pelaksana yang di ruang Rawat Inap RSUD Arifin Achmad Provinsi Riau yang bersedia menjadi responden

2. Pendidikan minimal D3 Keperawatan

3. Perawat yang bekerja lebih dari satu tahun sedangkan kriteria eksklusi adalah perawat pelaksana yang sedang dalam masa tugas belajar dan izin belajar dan yang sedang cuti (cuti hamil, cuti menikah, cuti sakit).

Penelitian dimulai dengan melakukan ethical clearance penelitian, selanjutnya setelah lulus kaji etik penelitian maka dilakukan pengambilan data penelitian yang dilakukan pada bulan Mei sampai dengan juni 2019.

Alat Pengumpulan data untuk mengukur budaya keselamatan pasien menggunakan kuesioner yang diadopsi dari kuesioner Hospital Survey On Patient Safety (HSPSC) yang mengukur 12 dimensi budaya keselamatan pasien di rumah sakit yang dipublikasikan oleh The Agency For Healthcare Research and Quality 
Yeni Yarnita dan Efitra, Analisis Faktor yang Berhubungan dengan Budaya Keselamatan Pasien pada Perawat di Ruang Rawat Inap RSUD Arifin Achmad Provinsi Riau

(AHRQ, 2016). Sedangkan alat pengumpulan data untuk mengukur factor yang berhubungan dengan budaya keselamatan pasien yaitu sikap perawat menggunakan kuesioner Safety Attitudes Questionnaire (SAQ) yang di keluarkan oleh WHO (2009), stres perawat menggunakan kuesioner International Stress Management Association (ISMA) (2013) serta kelelahan perawat dalam bekerja kuesioner berdasarkan Fatigue Asessment Scale (FAS) (Marjolein, D. 2012) dan untuk mengukur tim kerja perawat menggunakan kuesioner TeamStepps Teamwork Assessment Questionnaire (T$T A Q$ ) berdasarkan WHO (2009). Analisa data univariat dan bivariat yang dilakukan menggunakan program spss yang disajikan dalam bentuk distribusi frekuensi untuk melihat frekuensi karakteristik responden berdasarkan umur, jenis kelamin, pendidikan, lama kerja, budaya keselamatan pasien dan dimensi serta factor yang berhubungan dengan budaya keselamatan pasien di Instalasi Perawatan Intensive RSUD Arifin Achmad Provinsi Riau

\section{HASIL DAN PEMBAHASAN}

Tabel 1. Distribusi frekuensi hubungan sikap perawat dengan budaya keselamatan pasien pada perawat di ruang rawat Inap RSUD Arifin Achmad Provinsi Riau (N=131) 2017

\begin{tabular}{ccccccccc}
\hline No & Sitan perawat & \multicolumn{4}{c}{ Budaya keselamatan } & Jumlah & \multirow{2}{*}{ p(value) } \\
\cline { 3 - 7 } & & \multicolumn{2}{c}{ Negatif } & Positif & & & \\
\cline { 3 - 7 } & & $\mathrm{f}$ & $\%$ & $\mathrm{f}$ & $\%$ & $\mathrm{f}$ & $\%$ & \\
\hline 1 & Negatif & 49 & 67.1 & 24 & 32.9 & 73 & 100 & \multirow{2}{*}{0.001} \\
2 & Positif & 21 & 36.2 & 37 & 63.8 & 58 & 100 & \\
& Total & 70 & 53.4 & 61 & 46.6 & 131 & & \\
\hline
\end{tabular}

Sumber: data diolah

Data diatas menunjukkan bahwa terdapat hubungan sikap perawat dengan budaya keselamatan bahwa dengan $\mathrm{p}$ value $<0.05$ yaitu 0.001 . Dengan demikian perawat yang memiliki nilai-nilai serta perilaku serta kompetensi yang tidak sesuai dengan keselamatan pasien akan cendrung dimiliki oleh perawat yang menganggap negatif terhadap keselamatan pasien.

Hasil penelitian ini didukung oleh penelitian Azimi et al (2012) yang menyatakan bahwa terdapat kaitan antara sikap perawat dengan budaya keselamatan pasien. Sikap merupakan pernyataan evaluatif terhadap objek, orang atau peristiwa yang dapat berupa sikap negatif atau positif. Sikap terhadap budaya keselamatan meruapakan cara pandang perawat pelaksana terhadap pelasana terhadap pelaksanaan budaya keselamatan tersebut (Budihardjo, 2008).

Hasil penelitian memperlihatkan bahwa lebih dari separuh perawat memiliki budaya keselamatan negatif yaitu $70(53.4 \%)$ dan budaya keselamatan pasien yang positif berjumlah 61 (46.6\%). Hasil penelitian ini menunjukkan bahwa lebih banyak perawat yang memiliki nilai-nilai, kompetensi, sikap serta pola perilaku keselamatan pasien yang masih belum sesuai dengan yang diharapkan dalam budaya keselamatan pasien.

Hasil penelitian didukung oleh penelitian Nurmalia, (2013) tentang pengaruh program mentoring terhadap penerapan budaya keselamatan pasien didapat $52.2 \%$ perawat memiliki budaya keselamatan negatif dan $47.3 \%$ perawat memiliki budaya keselamatan positif. Sejalan dengan Penelitian Nivalinda (2013) diperoleh hasil $51.4 \%$ perawat memiliki budaya keselamatan pasien negative. Amaarapathy (2013) mengatakan bahwa budaya keselamatan pasien merupakan kewajiban dan tanggung jawab seluruh pegawai. Dalam hal ini pengawai adalah bagian dari organisasi merupakan ujung tombak dalam budaya keselamatan pasien.

Budaya keselamatan pasien dikatakan berhasil apabila semua elemen yang ada di dalam rumah sakit menerapkan budaya keselamatan pasien dalam pekerjaannya sehari-hari (Reiling, 2006). Sedangkan Beginta (2012) mengatakan bahwa upaya yang dapat dilakukan untuk meningkatkan budaya keselamatan adalah dengan mendorong setiap orang bertanggung jawab akan keselamatan terhadap diri sendiri, rekan kerja, pasien, dan pengunjung, mengutamakan keselamatan dan keuntungan di atas keutungan dan tujuan organisasi.

Weaver et al,. (2013) mengatakan bahwa mempromosikan budaya keselamatan pasien merupakan langkah utama dalam meningkatkan keselamatan pasien. Pemimpin merupakan motor penggerak untuk melakukan aktifitas sesuai dengan yang diharapkan organisasi. Promosi budaya keselamatan pasien yang baik merupakan pelaksanaan dari intervensi yang mendasar dari kepemimpinan yang akan merubah perilaku anggota tim. Sedangkan menurut Nivalinda (2013) Budaya keselamatan yang kuat membutuhkan kepemimpinan yang mampu menetapkan dan mengkomunikasikan visi keselamatan dengan jelas, menghargai dan memberdayakan staf untuk mencapai visi keselamatan pasien.

Dukungan yang dapat dilakukan oleh supervisor dapat berupa adanya pola komunikasi yang dilakukan secara timbal balik dua arah yang bersifat dukungan atau motivasi yang diberikan terhadap perawat pelaksana di ruang Rawat Inap RSUD Arifin Achmad Provinsi Riau sehingga akan mempelihatkan adanya dukungan supervisor atau pemimpin dalam membudayakan keselamatan pasien. Dengan semikian diharapkan dapat membentuk sebuah sikap yang mendukung budaya keselamatan pasien di rumah sakit.

Berdasarkan pernyataan di atas maka terlihat bahwa terdapat keterkaitan antara sikap perawat dengan budaya keselamatan pasien. Hal ini sesuai dengan pernyataan Ardana (2012) yang menyatakan bahwa budaya organisasi berperan penting membangun semangat kerja dan sikap para karyawan. Adanya budaya organisasi yang kuat dan telah berakar akan 
Yeni Yarnita dan Efitra, Analisis Faktor yang Berhubungan dengan Budaya Keselamatan Pasien pada Perawat di Ruang Rawat Inap RSUD Arifin Achmad Provinsi Riau

dapat memberikan kontribusi yang cukup signifikan bagi sikap dan perilaku anggota organisasi.

Sobirin (2005) yang menyatakan bahwa keberhasilan perubahan budaya diperlukan partisipasi anggota organisasi untuk berubah dan untuk merubah budaya organisasi tersebut memerlukan waktu yang cukup lama bahwa memerlukan waktu 5 sampai 10 tahun kedepan.

Tabel 2. Distribusi frekuensi hubungan Tim Kerja perawat dengan budaya keselamatan pasien pada perawat di ruang rawat Inap RSUD Arifin Achmad Provinsi Riau (N=131) 2017

\begin{tabular}{|c|c|c|c|c|c|c|c|c|}
\hline \multirow[t]{3}{*}{ No } & \multirow[t]{3}{*}{ Tim Kerja Perawat } & \multicolumn{4}{|c|}{ Budava keselamatan } & \multicolumn{2}{|c|}{ Jumlah } & \multirow[t]{2}{*}{$\mathrm{p}$ (value, } \\
\hline & & \multicolumn{2}{|c|}{ Negatif } & \multicolumn{2}{|c|}{ Positiff } & & & \\
\hline & & $\mathrm{f}$ & $\%$ & $\mathrm{f}$ & $\%$ & $\mathrm{f}$ & $\%$ & \multirow{4}{*}{0.017} \\
\hline \multirow{3}{*}{$\begin{array}{l}1 \\
2\end{array}$} & Kurang Baik & 41 & 65.1 & 22 & 34.9 & 63 & 100 & \\
\hline & Baik & 29 & 42.6 & 39 & 57.4 & 68 & 100 & \\
\hline & Total & 70 & 53.4 & 61 & 46.6 & 131 & & \\
\hline
\end{tabular}

Sumber: data diolah

Hasil penelitian hubungan tim kerja dengan budaya keselamatan pasien di ruang rawat inap RSUD Arifin Achmad Provinsi Riau menggunakan chi square didapatkan $p$ value $<0,05$ yaitu 0.017 yang artinya terdapat hubungan yang bermakna antara tim kerja dengan budaya keselamatan pasien di ruang Rawat Inap RSUD Arifin Achmad Provinsi Riau. Sejalan dengan penelitian Hasil penelitian Rachmawati (2011) yang menunjukan bahwa kerja sama tim berpengaruh positif dan signifikan terhadap budaya keselamatan pasien. Eiras, et al (2014) mengatakan bahwa tim yang baik adalah tim yang saling mendukung dan saling menghargai dalam melakukan tugas. Tracy (2006) menyatakan bahwa teamwork merupakan kegiatan yang dikelola dan dilakukan sekelompok orang yang tergabung dalam satu organisasi. Teamwork dapat meningkatkan kerja sama dan komunikasi di dalam dan diantara bagian-bagian organisasi. Biasanya teamwork beranggotakan orang-orang yang memiliki perbedaan keahlian sehingga dijadikan kekuatan dalam mencapai tujuan perusahaan. Dengan demikian adanya kerja sama tim yang baik akan meningkatkan budaya keselamatan pasien

Kerjasama tim yang telah di bangun pada ruang rawat Inap RSUD Arifin Achmad Provinsi Riau pada dasarnya dapat meningkatkan tercapainya tujuan yang diharapkan yakni adanya suatu pola kerja yang menghasilkan budaya keselamatan pasien pada ruang rawat inap RSUD Arifin Achmad Provinsi Riau. Apriningsih (2013) menyatakan bahwa kerjasama tim antar unit akan mempermudah suatu program keselamatan pasien, pelaksanaanya serta hasil, tindak lanjut kegiatan tersebut. Dengan adanya sistem yang menyeluruh maka budaya keselamatan akan dapat terbentuk dengan sendirinya pada pelayanan kesehatan.

Hasil penelitian tersebut juga didukung oleh penelitian Bodur \& Filiz (2010). Dimana hasil penelitiannya menunjukkan bahwan kerja sama tim (70\%) yang artinya telah memiliki kerjasama tim yang baik. Kerja sama tim yang baik dapat dilihat dalam memberikan pelayanan kesehatan dimana tim yang baik akan menghasilkan pelayanan kesehatan yang efektif, bertanggung jawab dan saling menghargai sesama anggota tim

Kerjasama tim yang telah di bangun pada ruang rawat Inap RSUD Arifin Achmad Provinsi Riau pada dasarnya dapat meningkatkan tercapainya tujuan yang diharapkan yakni adanya suatu pola kerja yang menghasilkan budaya keselamatan pasien pada ruang rawat inap RSUD Arifin Achmad Provinsi Riau. Apriningsih (2013) menyatakan bahwa kerjasama tim antar unit akan mempermudah suatu program keselamatan pasien, pelaksanaanya serta hasil, tindak lanjut kegiatan tersebut. Dengan adanya sistem yang menyeluruh maka budaya keselamatan akan dapat terbentuk dengan sendirinya pada pelayanan kesehatan. Dengan demikian hubungan budaya keselamatan dengan tim kerja merupakan dua komponan yang saling berkaitan. Hal ini dikarenakan tim kerja merupakan kelompok kerja yang terdiri dari individu yang akan melakukan aktifitas sesuai dengan tujuan dan fungsi dari tim kerja tersebut. Sedangkan budaya keselamatan merupakan nilai-nilai keselamatan yang dianut dan dibentuk berdasarkan kelompok atau organisasi.

Hasil penelitian tersebut juga didukung oleh penelitian Bodur \& Filiz (2010). Dimana hasil penelitiannya menunjukkan bahwan kerja sama tim (70\%) yang artinya telah memiliki kerjasama tim yang baik. Kerja sama tim yang baik dapat dilihat dalam memberikan pelayanan kesehatan dimana tim yang baik akan menghasilkan pelayanan kesehatan yang efektif, bertanggung jawab dan saling menghargai sesama anggota tim.

Tabel 3. Distribusi frekuensi hubungan Kelelahan Kerja perawat dengan budaya keselamatan pasien pada perawat di ruang rawat Inap RSUD Arifin Achmad Provinsi Riau (N=131) 2017

\begin{tabular}{llccccccc}
\hline No & Kelelahan kerja & \multicolumn{4}{c}{ Budaxa keselamatan } & Jumlah & $\mathrm{p}$ (value) \\
\cline { 3 - 7 } & & Negatif & \multicolumn{2}{c}{ Positif } & & & \\
\cline { 3 - 7 } & & $\mathrm{f}$ & $\%$ & $\mathrm{f}$ & $\%$ & $\mathrm{f}$ & $\%$ & \\
\hline 1 & Lelah & 38 & 66.7 & 19 & 33.3 & 57 & 100 & 0.013 \\
2 & Tidak Lelah & 32 & 43.2 & 42 & 56.8 & 74 & 100 & \\
& Total & 70 & 53.4 & 61 & 46.6 & 131 & & \\
\hline
\end{tabular}

Sumber: data diolah

Hasil penelitian hubungan kelelahan kerja dengan budaya keselamatan pasien di ruang rawat inap RSUD Arifin Achmad Provinsi Riau menggunakan chi square didapatkan $p$ value $<0,05$ yaitu 0.013 yang artinya terdapat hubungan yang bermakna antara kelelahan kerja dengan budaya keselamatan pasien di ruang Rawat Inap RSUD Arifin Achmad Provinsi Riau. 
Hasil penelitian ini sejalan dengan hasil penelitian Rogers (2012) menyatakan bahwa kekurangan kebutuhan tidur yang akan berdampak pada kelelahan pada perawat akan akan mempengaruhi keselamatan pasien. Hubungan yang bermakna antara budaya keselamatan pasien dengan faktor kelalahan kerja merupak an dua fenomena yang dapat terjadi disetiap pelayanan kesehatan. Hal ini diakibatkan oleh kelelahan yang dirasakan oleh individu akan mempengaruhi seluruh aktivitas individu tersebut baik secara fisik maupun secara mental.

Hasil penelitian juga di dukung oleh penelitian Hasil penelitian juga di dukung oleh penelitian Sandrawati (2013) bahwa kelelahan yang berkaitan dengan beban kerja yang tinggi pada perawat dapat mempengaruhi kelelahan yang berdampak pada kinerja dalam penerapan budaya keselamatan pasien. Hubungan antara budaya keselamatan dengan kelelahan perawat di ruang rawat inap RSUD Arifin Achmad Provinsi merupakan dua fenomena yang dapat terjadi disetiap pelayanan kesehatan. Hal ini diakibatkan oleh kelelahan yang dirasakan oleh individu akan mempengaruhi seluruh aktivitas individu tersebut baik secara fisik maupun secara mental. Orang akan mampu melakukan pekerjaannya dengan mudah apabila didukung oleh kondisi fisik yang baik yang akan mempengaruhi kekuatan secara psikologis.

Berdasarkan hasil penelitian hampir separuh perawat mengalami kelelahan dalam bekerja dan 74 orang (56.5\%) lebih dari separuh perawat tidak mengalami kelelahan. Hasil ini didukung oleh penelian Vilia (2014) di Instalasi Rawat Inap RSUD Abdul Moeloek Bandar Lampung dimana $56.7 \%$ perawat mengalami keleahan kerja. Penelitian ini juga didukung oleh penelitian Rizky (2015) di Instalasi rawat Inap RS Surabaya bahwa $51.9 \%$ perawat mengalami kelalahan kerja. Kelelahan kerja menurut Suma'mur (2009), bahwa kelelahan merupakan penurunan ketahanan dan daya tubuh untuk melakukan pekerjaan. Menurut Setiyowati (2010), bahwa kelelahan kerja tidak dapat didefinisikan tetapi dapat dirasakan sehingga penentuan kelelahan kerja dapat diketahui secara subjektif berdasarkan perasaan yang dialami tenaga kerja

Tabel 4. distribusi frekuensi hubungan Stress Kerja perawat dengan budaya keselamatan pasien pada perawat di ruang rawat Inap RSUD Arifin Achmad Provinsi Riau (N=131) 2017

\begin{tabular}{llccccccc}
\hline No & Stress Kerja & \multicolumn{4}{c}{ Budaxa keselamatan } & Jumlah & p (value) \\
\cline { 3 - 6 } & & Negatif & \multicolumn{2}{c}{ Positif } & & & \\
\cline { 3 - 7 } & & $\mathrm{f}$ & $\%$ & $\mathrm{f}$ & $\%$ & $\mathrm{f}$ & $\%$ & \\
\hline 1 & Stress & 28 & 63.6 & 16 & 36.4 & 44 & 100 & 0.139 \\
2 & Tidak Stress & 42 & 48.3 & 45 & 51.7 & 87 & 100 & \\
& Total & 70 & 53.4 & 61 & 46.6 & 131 & & \\
\hline
\end{tabular}

Sumber: data diolah

Hasil penelitian hubungan stres kerja dengan budaya keselamatan pasien di ruang rawat inap RSUD
Arifin Achmad Provinsi Riau menggunakan chi square didapatkan $p$ value $>0,05$ yaitu 0.139 yang artinya tidak terdapat hubungan yang bermakna antara stres kerja perawat dengan budaya keselamatan pasien di Ruang Rawat Inap RSUD Arifin Achmad Provinsi Riau.

Hasil penelitian sejalan dengan penelitian Chaerunisa, (2009) diperoleh bahwa tidak terdapat hubungan antara perilaku implementasi parien safety dengan stres perawat. Hasil penelitian ini juga didukung oleh penelitian Ema Rachmawati, (2011) bahwa faktor yang paling berhubungan dengan budaya keselamatan adalah kepemimpinan transformasional, adanya kerja sama tim serta kesadaran individu Russeng (2007) mengatakan bahwa apabila perawat memiliki stres kerja yang tinggi maka akan menurunkan kualitas kerja perawat.Berdasarkan hasil penelitian dan teori diatas maka stres kerja memiliki pengaruh negatif terhadap budaya keselamatan pasien, namun tidak memiliki hubungan yang signifikan pada batas nilai yang ditentukan.

Stres kerja pada perawat merupakan salah satu permasalahan dalam manajemen sumber daya manusia di Rumah Sakit. Stres merupakan suatu respons adaptif terhadap suatu situasi yang dirasakan menantang atau mengancam kesehatan seseorang (Sopiah, 2008). Ashar (2008) menyatakan bahwa stres yang dialami tenaga kerja sebagai hasil atau akibat lain dari proses bekerja, yang dapat berkembang menjadikan tenaga kerja sakit fisik dan mental, sehingga tidak dapat bekerja lagi secara optimal.

\section{Pembahasan \\ Variabel yang Paling Dominan dengan Budaya Keselamatan Pasien}

Variabel yang paling berhubungan/bermakna dengan budaya keselamatan pasien adalah variabel sikap perawat dengan $v$ palue 0.001 . Sikap merupakan kecenderungan bertindak atau keadaan diri dalam manusia yang menggerakkan untuk bertindak atau berbuat oleh karena adanya stimulus atau objek tertentu Simorangkir (2014).

Sikap sebagai faktor yang paling dominan dengan budaya keselamatan di ruang rawat inap RSUD Arifin Achmad Provinsi Riau berkaitan dengan adanya pengaruh dari faktor pengalaman pribadi, pengaruh orang lain yang dianggap penting seperti team kerja, pengaruh kebudayaan sebelumnya, serta pendidikan yang dimiliki individu

\section{SIMPULAN}

Berdasarkan hasil penelitian faktor yang berhubungan dengan budaya keselamatan pasien adalah faktor sikap perawat, tim kerja perawata, dan kelelahan perawatt. Sedangkan untuk faktor stres kerja perawat tidak memiliki hubungan dengan budaya keselamatan pasien. 
Yeni Yarnita dan Efitra, Analisis Faktor yang Berhubungan dengan Budaya Keselamatan Pasien pada Perawat di Ruang Rawat Inap RSUD Arifin Achmad Provinsi Riau

\section{DAFTAR PUSTAKA}

Ashar Sunyoto. (2008). Psikologi Industri dan Organisasi. Jakarta: UI Pres

Aspden, P, et al., (2007). Preventing medical error: Quality chasm series

Amaarapathy., Sridharan., Perera \& Handa., (2013).Factors Affecting Patient Safety Culture In A Tertiary Care Hospotal In Sri Langka.ISSN 2277

8616.http://www.nrls.npsa.nhs.uk/resourses/patien t-safety-topics/human-factors-patient-safetyculture

Azimi, Et AL (2012) influence of training on patient safety culture: a nurse attitude improvement perspective "international journal of hospital research. 1(1):51-56www.ijhr.tums.ac.ir. Research article

Ardana, Komang. 2012. Manajemen Sumber Daya Manusia. Yogyakarta:Graha Ilm

Apriningsih, Desmawati, Jesro, M. (2013) Kerjasama tim dalam budaya keselamatan pasien Di $r s x$ (studi kualitatif di suatu rsud di propinsi jawa barat) jurnal ilmiah kesehatan, 5(3 ); sept 2013 http://lp3m.thamrin.ac.id/upload/apriningsih.pdf

Anggraeni , D. (2016). pengaruh budaya keselamatan pasien terhadap sikap melaporkan insiden pada perawat di instalasi rawat inaprumah sakit tk. Ii $d r$. Soepraoen. Jurnal aplikasi manajemen. Vol 14 no 42

Beginta, R. (2012) Pengaruh budaya keselamatan pasien, gaya kepemimpinan, tim kerja, terhadap Persepsi pelaporan kesalahan pelayanan oleh perawat di unit rawat inap rumah sakit umum Daerah kabupaten bekasi [tesis]. Bekasi: universitas indonesia. Tidak dipublikasika

Bodur, S \& Filiz, E. (2010). Validity and reliability of turkish version of'Hospital Survey on Patient Safety culture" and perception of patient safety in public hospitals in Turkey. http://www.biomedcentral.com/1472-6963/10/28

Buerhaus, P,. (2011). Lucian Leape On Patien Safety In U.S Hospital Jurnal Nursing Of Scholarship, 4 (36), 366-370. (available at) http://www.proquest.umi.com/pqdweb

Brady,S., O’Connor, N., Burgermeister, D., \& Hanson, P. (2012). The Impact of mindfulness meditation in promoting a culture of safety on an acute psychiatric unit. Perspectives in psychiatric care, 48(3), 129-137.doi:10.1111/j. 17446163.2011.00315.x

Budihardjo , A. (2008) pentingnya safety culture dirumahsakitupaya meminimalkan adverse events .jurnal manajemen bisnis vol 1 no 1 (53-70)

Cahyono, Suharjo B., 2008. Membangun Budaya Keselamatan Pasien dalam Praktik Kedokteran. Yogyakarta : Kanisius
Chaerunisa. (2009). Pengaruh stres kerja perawat terhadap perilaku implementasi patient safetydi IGD RS Panembahan Senopati Bantul. Tesis. Tidak dipublikasikan

Departemen Kesehatan (2006). Utamakan Keselamatan Pasien. (http://rsbt.or.id/kkprs/data/panduan.pdf diakses Tanggal 2 Mei 2016)

Eiras, M., Escoval, A., Isabel, M. G., Silva-Fortes, C (2014). The hospital survey on patient safety culture in Portuguese hospitals: Instrument validity and reliability International Journal of Health Care Quality Assurance11122.

Fujita, S., Seto, K,. Ito, S., Wu, Y., huang. C.-C., \& hasegawa, T. (2013). The characteristics of patient safety culture in Japan, Taiwan and the United States. BMC Health services research, 13,20-20. Doi: 10.1186/1472-6963-13-20

Hammer, et al,. (2011). Psychometric properties of the hospital survey on patient savety culture for hospital management (HSOPS_M). BMC health services research

Najjar S, et al,. (2013). The Arabic version of the hospital survey on patient safety culture: a psychometric evaluation in a Palestinian sample. http://www.biomedcentral.com/1472-6963/13/193

Nivalinda (2013). pengaruh motivasi perawat dan gaya kepemimpinan kepala Ruang terhadap penerapan budaya keselamatan pasien oleh Perawat pelaksana pada rumah sakit pemerintah di semarang. jurnal managemen keperawatan . Volume 1, no. 2, november 2013; 138-145

Notoatmodjo, S. 2010. Metodologi Penelitian Kesehatan. Jakarta: PT Rineka Cipta .

Nurmalia, D (2013). pengaruh program mentoring terhadap penerapan buday keselamatan pasien.http://jurnal.unimus.ac.id/index.php/JMK/a rticle/view/1002/1051

Raftopoulos, V,. Pavlakis, A., (2013) safety climate in 5 intensive care unit : A natiowide hospital survey using the greek-cypriot version of the safety attitudes questionnaire. $\quad$ http://dx. Doi.org/10.1016/J.Jere2012.04.013

Rachmawati. E. (2011). Model Pengukuran Budaya Keselamatan Pasien Di Rs Muhammadiyah Aisyiyah Tahun 2011,prosiding penelitian bidang ilmu eksakta. Hal 11-34

Reiling, J. G. (2006). Creating a culture of patient safety through innovative hospital desigh. Journal advance in patient safety. 2 (20), 1-5 http://www.ahrq.gov

Rogers, A, E.,(2012). Patient Safety And Quality : An Evidence-based Handbook for nurse. http://www.ncbi.nlm.nih.gov/books/NBK2645

Rizky, (2015). analisis tingkat kelelahan kerja berdasarkan Beban kerja fisik perawat di instalasi rawat inap Rsud haji surabaya. the indonesian 
journal of occupational safety and health, vol. 4, : 93-102

Russeng, SS., Usman, M., Saleh., LM. 2007. Stres Kerja pada Perawat di Instalasi Rawat Inap Rumah Sakit Dr. TAdjuddin Chalid Makassar. Jurnal Media Kesehatan Masyarakat Indonesia UNHAS Volume 3 No.1.

Sandrawati, 2013, Rekomendasi Untuk Meningkatkan Kepatuhan Penerapan Surgical Safety Checklist di Kamar Bedah Di RSK St. Vincentius a Paulo (RKZ) Surabaya, Skripsi

Sammer, E, C.,James, B, R.,(2011). Patient safety culture: The nursing unit leader's role. OJIN: the online journal of issues in nursing .Vol. 16, No.3, Manuscript 3. DOI: 10.3912/OJIN.vol16 no3man03

Sastroasmoro, S. 2011. Dasar-Dasar Metodologi Penelitian Klinis. Jakarta : Sagung Seto.

Sobirin Ahmad. (2005). Privatisasi: implikasinya terhadap perubahan Perilaku karyawan dan budaya organisasi. http://jurnal.uii.ac.id/index.php/JSB/article/view/9 $\underline{67 / 876}$

Sopiah. 2008. Perilaku organisasional. Yogyakarta: Andi

Sugiyono, (2011). Statistika untuk Penelitian. Bandung: CV Alfabeta.

Suma'mur, 2009. Higienen perusahaan dan kesehatan kerja (hiperkes). Jakarta: sagung seto

Setiyowati, D. (2010). Hubungan kepemimpinan efetif head nurse dengan penerapan budaya keselamatan pasien oleh perawat pelaksana di RSUPN dr. Cipto mangunkusumo. Depok: FIK UI . tesis tidak dipublikasikan

Tracy, Brian, 2006. Pemimpin Sukses, Cetakan Keenam, Penerjemah: Suharsono dan Ana Budi Kuswandani, Penerbit Pustaka Delapatrasa, Jakarta.

Vilia, Adelina. 2014. Faktor-Faktor yang Berhubungan dengan Kelelahan Kerja Pada Perawat di Instalasi Rawat Inap RSUD DR. H. Abdul Moeleok Bandar Lampung. Fakultas Kedokteran Universitas Lampung: Bandar Lampung ( http://digilib.unila.ac.id/2288 )

Weaver, et al. (2013). Promoting a culture of safety as a patient safety strategy. Ann Intern Med. 2013;158(5_Part_2):369-374. doi:10.7326/00034819-158-5201303051-00002.

World Health Organizations (WHO). (2009). Surgical safety check list reinforces accepted safety practices and foster better communication and teamwork. 